\title{
Contabilidade
}

\section{CONSTRUÇÃO DE UMA FERRAMENTA DE APOIO NA GESTÃO DA \\ TRANSPARỂNCIA E ACESSIBILIDADE DA INFORMAÇÃO USANDO A ABORDAGEM MCDA-C}

\author{
Nome: Gabriel Nilson Coelho \\ Instituição: Universidade Federal de Santa Catarina - UFSC \\ E-mail: gn.coelho@ hotmail.com

\section{Nome: Sandra Rolin Ensslin} \\ Instituição: Universidade Federal de Santa Catarina - UFSC \\ E-mail: csensslin@gmail.com \\ Nome: Sergio Murilo Petri \\ Instituição: Universidade Federal de Santa Catarina - UFSC \\ E-mail: smpetri@gmail.com
}

Resumo: Este estudo objetiva construir um modelo de avaliação de desempenho multicritério construtivista para apoiar a gestão da transparência e acessibilidade da informação no Departamento de Contabilidade e Finanças de uma Universidade Federal. A presente pesquisa possui caráter exploratório-descritivo. A escolha da metodologia construtivista é baseada na possibilidade de geração de conhecimento no decisor, que neste caso é o diretor do departamento, o qual percebe a Metodologia Multicritério de Apoio à Decisão Construtivista (MCDA-C) como instrumento de intervenção adequado e útil para embasar suas decisões, tonando assim este trabalho viável. Os principais resultados encontrados com a elaboração do modelo foram: a identificação de três áreas de preocupação: admissão, remuneração e aposentadoria, sendo construídos nove descritores para avaliar o status quo das atividades desempenhadas. Foi constatado que dois descritores apresentaram níveis de desempenho classificados como comprometedor. Para estes foram sugeridas ações de melhoria na etapa de recomendações. As atividades críticas não são exclusivas do setor, conforme analisado no cotejamento de resultados, são desafios presentes em outros estudos, o que indica um horizonte de pesquisa amplo na área.

Palavras-chave: Avaliação de desempenho, Transparência, Metodologia MCDA-C.

\section{BUILDING A SUPPORTING TOOL FOR THE MANAGEMENT OF TRANSPARENCY AND INFORMATION ACCESSIBILITY USING THE MCDA-C APPROACH}

Abstract: This study aims to build a multicriteria constructivist performance evaluation
model to support the management of information transparency and accessibility in the
Accounting and Finance Department of the Federal University of Santa Catarina. The
present research is exploratory-descriptive. The choice of the constructivist methodology
is based on the possibility of generating knowledge in the decision maker, who in this
case is the department director, who perceives the Multicriteria Methodology of Support 


\section{Revista \\ UNEMAT de \\ Contabilidade}

v. 10, n. 19,2021

to the Constructivist Decision (MCDA-C) as an appropriate and useful intervention tool to support their decisions, thus making this work feasible. The main results obtained with the elaboration of the model were: the identification of three areas of concern: admission, compensation and retirement, nine descriptors were constructed to evaluate the status quo of the activities performed. It was found that two descriptors presented levels of compromising performance. For these, improvement actions were suggested at the recommendations stage. Critical activities are not unique to the sector, as analyzed in the comparison of results, are challenges present in other studies, which indicates a broad research horizon in the area.

Keywords: Performance evaluation, Transparency, Methodology MCDA-C.

\section{INTRODUÇÃO}

A Lei 12.527/2011 - Lei de Acesso à Informação (LAI) - estabelece que as informações de interesse coletivo deverão ser divulgadas pelos órgãos públicos, de maneira espontânea e proativa, independentemente de solicitações. A LAI é válida para órgãos de União, Estados, Distrito Federal e Municípios, incluindo empresas públicas e autarquias - determina que a publicidade dos dados públicos deve ser o preceito geral e o sigilo, uma exceção.

Conforme o artigo 5, inciso XXXIII da Constituição da República de 1988 “todos têm o direito a receber dos órgãos públicos informações de seu interesse particular, ou de interesse coletivo ou geral, que serão prestadas no prazo da lei, sob pena de responsabilidade, ressalvadas aquelas cujo sigilo seja imprescindível à segurança da sociedade e do Estado". A publicidade, portanto, tem o condão de evidenciar a objetivação da aplicação dos princípios constitucionais da administração pública, dando a necessária noção de transparência na condução da coisa pública exigida pela sociedade. As universidades federais brasileiras, como entidades públicas, estão obrigadas a cumprir as regras de transparência e prestação de contas. Bezerra, Borges e Valmorbida (2012) apontam que ocorre uma relativa falta de publicidade na divulgação da prestação de contas dessas instituições na Internet.

Crozatti (2002) aponta que existe uma evolução nos modelos de gestão, vinculada à inovação tecnológica, que vem gerar conceitos e modelos de Avaliação de Desempenho, que sejam capazes de adequar a organização ao ambiente competitivo. Neste contexto o olhar construtivista na tomada de decisão permite a criação de modelos que representem a realidade da estrutura avaliada. O propósito da Metodologia Multicritério de Apoio à Decisão - Construtivista (MCDA-C) é a construção do conhecimento no decisor do ambiente sob avaliação (Ensslin, Ensslin et al., 2020). 


\section{Revista

Nesta conjuntura, surge a pergunta de pesquisa que orienta o trabalho: Quais os critérios a serem considerados em um modelo que pretenda apoiar a gestão da transparência e acessibilidade da informação para um departamento de uma Universidade Federal? Assim, o objetivo geral deste estudo é: elaborar um modelo de avaliação de desempenho multicritério construtivista para apoiar a transparência e acessibilidade da informação para o Departamento de Contabilidade e Finanças de uma Universidade Federal usando a abordagem MCDA-C.

Para dar conta do objetivo estabelecido acima, os autores selecionaram a Metodologia Multicritério de Apoio à Decisão Construtivista (MCDA-C), por acreditar que esta, partindo de um paradigma construtivista, consegue encapsular as percepções e experiências dos envolvidos no processo (Igarashi, Ensslin, Ensslin \& Paladini, 2008).

A escolha da metodologia construtivista é baseada na possibilidade de geração de conhecimento no decisor, que neste caso é o Diretor do Departamento, responsável legal pela gestão. A originalidade e viabilidade justificam a construção deste estudo, visto que na revisão da literatura realizada não foram encontrados estudos com a mesma proposta e a necessidade e interesse do gestor por uma metodologia que auxilie a tomada de decisão somada ao fato de que o autor do trabalho (que atua como facilitador) é servidor atuante no departamento tornam o trabalho viável.

Os dispositivos de transparência ativa previstos no decreto de regulamentação da LAI, por exemplo, não estão integralmente presentes nos portais e, quando estão, nem sempre remetem ao conteúdo respectivo (Gama \& Rodrigues, 2016). Sobre o tema, Azevedo, Lyrio, Lunkes e Alberton (2016) realizaram uma pesquisa para verificar o nível de transparência dos sites das universidades federais no sul do Brasil no ano de 2014 com base no que a legislação brasileira determina. Apontaram que as universidades ainda podem melhorar, apresentado informações mais detalhadas e com melhor acesso ao conteúdo e encaminhamento de pedidos de acesso à informação. $\mathrm{O}$ alcance do objetivo do presente estudo permite lançar raízes para elaboração de futuros modelos de avaliação de desempenho multicritério construtivista para apoiar a transparência e a acessibilidade da informação nos departamentos de contabilidade e finanças de Universidades Federais, alcançando assim futuramente um modelo genérico que pode ser utilizado em diferentes contextos. 


\section{REFERENCIAL TEÓRICO}

Para avançar no conhecimento da temática, a presente seção tem por objetivo examinar a literatura pertinente ao desenvolvimento da pesquisa. A preocupação contida nesta revisão de literatura consiste em apresentar um panorama geral sobre o processo de tomada de decisão, o propósito da metodologia multicritério e sua aplicabilidade.

\subsection{Processo de tomada de decisão e Metodologia Multicritério de Apoio à Decisão}

Segundo Megginson et al. (1986, p. 162), “a tomada de decisão pode ser definida como a seleção consciente de um curso de ação dentre as alternativas disponíveis para obter um resultado desejado". Stoner e Freeman (1995) indicam que uma decisão tomada em condições de alto grau de certeza é aquela subsidiada por informações precisas, mensuráveis e confiáveis enquanto a decisão tomada em condições de incerteza é aquela em que a situação é de imprevisibilidade, ou seja, sem as informações necessárias. O processo de tomada de decisão é exemplificado na Figura 1.

Figura 1:Processo de Tomada de Decisão

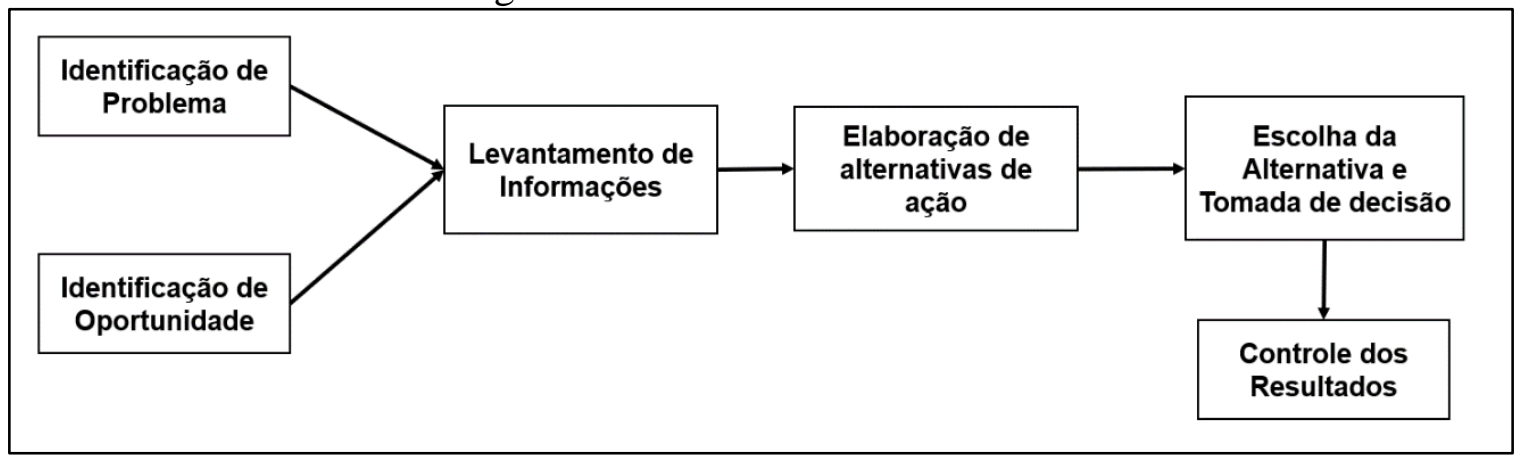

Fonte: Adaptado de Oliveira (2001, p. 41)

Segundo Gomes et al. (2014), o ato de decidir é uma ação complexa, uma vez que concerne em o que decidir, pois uma decisão equivocada pode incorrer em problemas irreversíveis. Para lidar com as decisões, a ciência disponibiliza os Sistemas de que suportam as decisões, ou Sistemas de Apoio à Decisão (SAD). Estes sistemas auxiliam as pessoas a tomarem decisões alinhadas com seus valores e preferências (Ensslin, Ensslin et al., 2020).

Os sistemas de informação desempenham papel relevante nas organizações. Os sistemas de informação transformam dados em informação. Os dados armazenados são sequências de fatos brutos que representam eventos que ocorreram nas organizações ou no ambiente físico, antes de terem sido organizados e arranjados de uma forma que as 
pessoas possam entendê-los e usá-los. Ou seja, dados transformam-se em informação quando "apresentados em uma forma significativa e útil” (Laudon e Laudon, 2007).

Segundo Coelho (2019) a literatura acadêmica referente a avaliação de desempenho, a criação de sistemas e sua relação com a tomada de decisão cresceu e evoluiu ao longo dos anos alcançando popularidade na prática e na pesquisa.

Um desses possíveis sistemas pode ser obtido por meio da Metodologia Multicritério de Apoio à Decisão - Construtivista (MCDA-C), no qual o propósito é a construção do conhecimento no decisor do ambiente sob avaliação (Ensslin, Ensslin et al , 2020). Segundo os autores a MCDA-C propicia ao decisor melhor entender o contexto a ser analisado.

\subsection{Aplicabilidade do Modelo e Arcabouço Legal para o presente Estudo}

A MCDA-C propicia ao decisor melhor entender o contexto a ser analisado. A Tabela 1 apresenta estudos que fizeram uso da metodologia em diferentes contextos dentro do âmbito do setor público:

Tabela 1 - Estudos Similares

\begin{tabular}{|l|l|}
\hline \multicolumn{1}{|c|}{ Referência } & \multicolumn{1}{|c|}{ Objetivo } \\
\hline $\begin{array}{l}\text { Araújo, S. S., dos Santos } \\
\text { Matos, L., \& Ensslin, S. R. } \\
\text { (2021) }\end{array}$ & $\begin{array}{l}\text { Estruturar um modelo para apoiar a gestão da Coordenadoria de } \\
\text { Processos Licitatórios do Hospital Universitário Professor Polydoro } \\
\text { Ernani de São Thiago da Universidade Federal de Santa Catarina, } \\
\text { Utiliza-se a metodologia Multicritério de Apoio à Decisão-Construtivista } \\
\text { (MCDA-C). }\end{array}$ \\
\hline $\begin{array}{l}\text { Corrêa Chaves, L., Ensslin, L., } \\
\text { Rolim Ensslin, S., \& } \\
\text { Bortoluzzi, S. C. (2020) }\end{array}$ & $\begin{array}{l}\text { Construir um modelo utilizando a Metodologia Multicritério de Apoio à } \\
\text { Decisão - Construtivista (MCDA-C) que subsidie o processo de } \\
\text { desenvolvimento de software para avaliar um sistema de gestão. }\end{array}$ \\
\hline $\begin{array}{l}\text { Asato, A. O., dos Santos, L. } \\
\text { M. R., dos Santos, E. A., \& } \\
\text { Zandavalli, C. B. (2020). }\end{array}$ & $\begin{array}{l}\text { Propor um modelo de gestão baseado em dois instrumentos de gestão } \\
\text { institucional) subsidiados por aspectos orçamentários de uma } \\
\text { universidade federal localizada na região Centro-Oeste brasileira, por } \\
\text { meio da aplicação do modelo multicritério de apoio à decisão } \\
\text { construtivista (MCDA-C). }\end{array}$ \\
\hline $\begin{array}{l}\text { Lopes, A. B. (2019). } \\
\text { Apresentar o levantamento de critérios para a análise de } \\
\text { viabilidade de obras públicas utilizando a Metodologia de Análise } \\
\text { Multicritério de Apoio a Decisão, que poderá possibilitar a diminuição } \\
\text { dos índices de fracasso em projetos da construção civil. }\end{array}$ \\
\hline
\end{tabular}

Fonte: Elaborado pelo Autor (2021).

É possível inferir por meio da verificação dos estudos relacionados na Tabela que as leis e regulamentos do setor público impactam na construção dos modelos, desta forma são elencados abaixo os principais regulamentos que impactam neste estudo de caso. 
Em termos jurídicos, "Arcabouço Legal” pode ser entendido como leis e decisões judiciais que dão sustentação a um determinado fato jurídico. A importância deste arcabouço referente à transparência e acessibilidade à informação em âmbito nacional pode ser percebido por meio da quantidade de princípios, leis e normativos que regulam o tema. Na sequência são apresentados os principais Instrumentos de políticas públicas de informação no Brasil.

a) Artigo 37 da Constituição Federal de 1988 - Estabelece o princípio da publicidade como obrigatoriedade de publicidade dos atos, programas, serviços e campanhas do serviço público, devendo ter caráter educativo, informativo ou de orientação social, não podendo haver promoção pessoal da autoridade ou servidores públicos. Ensslin et al. (2008) e Cruz e Ferreira (2008) afirmam que o Princípio da Publicidade não pode ser confundido com o princípio da transparência, pois a transparência inclui o princípio da publicidade.

b) Lei $\mathbf{n}^{\circ}$ 101/2000 (Lei da Responsabilidade Fiscal) - A Lei de Responsabilidade Fiscal reforça o Princípio da Transparência. Cruz, Platt Neto e Vieira (2006) afirmam que a responsabilidade na gestão fiscal pressupõe uma ação planejada e transparente.

c) Decreto ${ }^{\circ}$ 5.482/2005 (Portal Transparência Pública) - Decreto que trata da divulgação de dados e informações pelos órgãos e entidades da administração pública federal, por meio da Internet (Brasil, 2005).

d) LC ${ }^{\circ}$ 131/2009 (Lei da Transparência) - Legislação que determina a disponibilização, em tempo real, de informações pormenorizadas sobre a execução financeira e orçamentária da União, Estados, Distrito Federal e Municípios (Brasil, 2009).

e) Lei $n^{\circ}$ 12.527/2011 (Lei de Acesso à Informação Pública) - Legislação que regula o acesso a informações e dispõe sobre os procedimentos que devem observados pela União, Estados, Distrito Federal e Municípios, para garantir o acesso a informações (Brasil, 2011).

Outros normativos como a Portaria Interministerial $n^{\circ} 140 / 2006$ que disciplina a divulgação de dados e informações pelos órgãos e entidades da Administração Pública Federal, a Portaria CGU nº 277, de 7 de fevereiro de 2013; que institui o Programa Brasil Transparente com objetivo de apoiar a implementação da LAI. Contudo a existência deste 
arcabouço não garante o cumprimento da legislação. Gama e Rodrigues (2016) apontam que a existência de instrumentos que obrigam a transparência ativa não é garantia de sua implementação em curto prazo.

\section{METODOLOGIA DA PESQUISA}

A presente pesquisa possui caráter exploratório-descritivo. Como se pretendeu construir um modelo personalizado para apoiar a gestão da transparência e acessibilidade da informação do DCF -UFSC, utilizou-se, como procedimento técnico, o estudo de caso. A coleta de dados é caracterizada de natureza primária, visto que os dados serão coletados por meio de entrevistas semiestruturadas com o diretor do departamento. Quanto à abordagem do problema, este estudo caracteriza-se como qualitativo na fase de estruturação e recomendação da metodologia Multicritério de Apoio à DecisãoConstrutivista (MCDA-C) (Richardson, 1999).

\subsection{Procedimentos para Seleção do Material para Compor o Referencial Teórico}

A literatura nacional foi contemplada por meio de busca na base de dados Google Academics, foram estipulados 2 eixos de pesquisa. No primeiro foi utilizada a palavrachave "transparência" e "universidade" no segundo eixo resultando em 522 trabalhos. Os estudos foram filtrados de acordo com o seu alinhamento na seguinte sequência: alinhamento do título, alinhamento do resumo, disponibilidade do estudo e alinhamento integral do artigo. Ao final, o portfólio bibliográfico nacional restou composto de 12 artigos, que representaram a literatura nacional que guarda relação com o estudo proposto.

A Tabela 2 apresenta os autores, o ano e uma síntese do objetivo de cada estudo.

Tabela 2- Portfólio Bibliográfico do estudo

\begin{tabular}{|ll|}
\hline \multicolumn{1}{|c|}{ Autor e Ano } & \multicolumn{1}{c|}{ Objetivo } \\
Lyrio, Brotti, & Construir um modelo para avaliar o grau de transparência das informações nas \\
$\begin{array}{l}\text { Ensslin \& Ensslin } \\
\text { (2009). }\end{array}$ & $\begin{array}{l}\text { Demosntrações Financeiras publicadas por uma Instituição Pública de Ensino } \\
\text { Superior (IPES) brasileira. }\end{array}$ \\
$\begin{array}{l}\text { Oliveira Bezerra, } \\
\text { Borges \& }\end{array}$ & $\begin{array}{l}\text { Demonstrar as práticas de publicidade da UDESC na Internet e avaliá-las em } \\
\text { relação à legislação. }\end{array}$ \\
$\begin{array}{l}\text { Valmorbida } \\
\text { (2012). }\end{array}$ & \\
$\begin{array}{l}\text { Gama \& Rodrigues } \\
\text { (2016). }\end{array}$ & Verificar o comportamento da demanda por informações contábeis nas \\
Rezende Gama \& & Aniversidades públicas federais após a edição da Lei de Acesso à Informação. \\
Medleg Rodrigues & universidade federal brasileira e identificar as perspectivas e desafios dos \\
$(2016)$. & gestores públicos em relação a esta legislação. \\
\hline
\end{tabular}




\begin{tabular}{|c|c|}
\hline Valmorbida (2012) & $\begin{array}{l}\text { Investigar os procedimentos para Gestão de Conteúdo como apoio ao processo } \\
\text { de tomada de decisão no âmbito da Pós-Graduação Stricto sensu da UFPR. } \\
\text { Desenvolver um modelo personalizado de avaliação de desempenho, que } \\
\text { oportunizasse ao decisor: expandir seu entendimento sobre o contexto decisório, } \\
\text { identificar, mensurar e integrar os aspectos julgados por ele como relevantes } \\
\text { para monitorar e aperfeiçoar a gestão. }\end{array}$ \\
\hline $\begin{array}{l}\text { Costa \& Neto } \\
(2016) \text {. }\end{array}$ & $\begin{array}{l}\text { Apresentar um estudo sobre o direito à informação, o acesso e como se dá esse } \\
\text { processo no âmbito de uma instituição pública federal de ensino superior. }\end{array}$ \\
\hline Sediy & $1 \mathrm{de}$ \\
\hline $\begin{array}{l}\text { Oliveira Reis, \& } \\
\text { dos Anjos (2016). }\end{array}$ & $\begin{array}{l}\text { Ensino Superior a fim de contribuir para o fortalecimento da transparência } \\
\text { pública. }\end{array}$ \\
\hline $\begin{array}{l}\text { Esteves, Lourenço } \\
\text { \& Sá (2017). }\end{array}$ & $\begin{array}{l}\text { Entender de que forma as Instituições de Ensino Superior podem aumentar a sua } \\
\text { transparência junto de um dos seus principais stakeholders externos, a } \\
\text { comunidade empresarial, questionando-os diretamente sobre as suas } \\
\text { necessidades informacionais. }\end{array}$ \\
\hline Ram & Analisar o grau de adesão e de disclosure pelas Instituições de Ensino Superior \\
\hline Colares (2016). & $\begin{array}{l}\text { vinculadas ao sistema federal de ensino público aos procedimentos contábeis } \\
\text { patrimoniais (depreciação, reavaliação e impairment) após a implantação das } \\
\text { Normas Internacionais de Contabilidade aplicadas ao setor público (NBC T } 16.9 \\
\text { e NBC T 16.10). }\end{array}$ \\
\hline Silva Leite(2017). & $\begin{array}{l}\text { Verificar o potencial do SICAP como um instrumento de transparência nas } \\
\text { informações prestadas por uma fundação privada da Comarca de Dourados-MS. }\end{array}$ \\
\hline $\begin{array}{l}\text { Carvalho Almeida, } \\
\text { \& Freire (2015). }\end{array}$ & $\begin{array}{l}\text { Propor a adequação do portal Transparência UFPB à Lei de Acesso à } \\
\text { Informação, com a inclusão de todas as informações tidas como obrigatórias } \\
\text { pelo referido normativo legal. }\end{array}$ \\
\hline
\end{tabular}

Fonte: Dados da pesquisa (2021).

\subsection{Etapas do Modelo Multicritério Construtivista e Procedimentos para Coleta de}

\section{Dados}

A operacionalização do processo de apoio à decisão, com a utilização da abordagem MCDA-C, é realizada em três etapas: estruturação, avaliação e recomendação, conforme demonstrado na Figura 2. 
Figura 2 - Etapas do MCDA-C

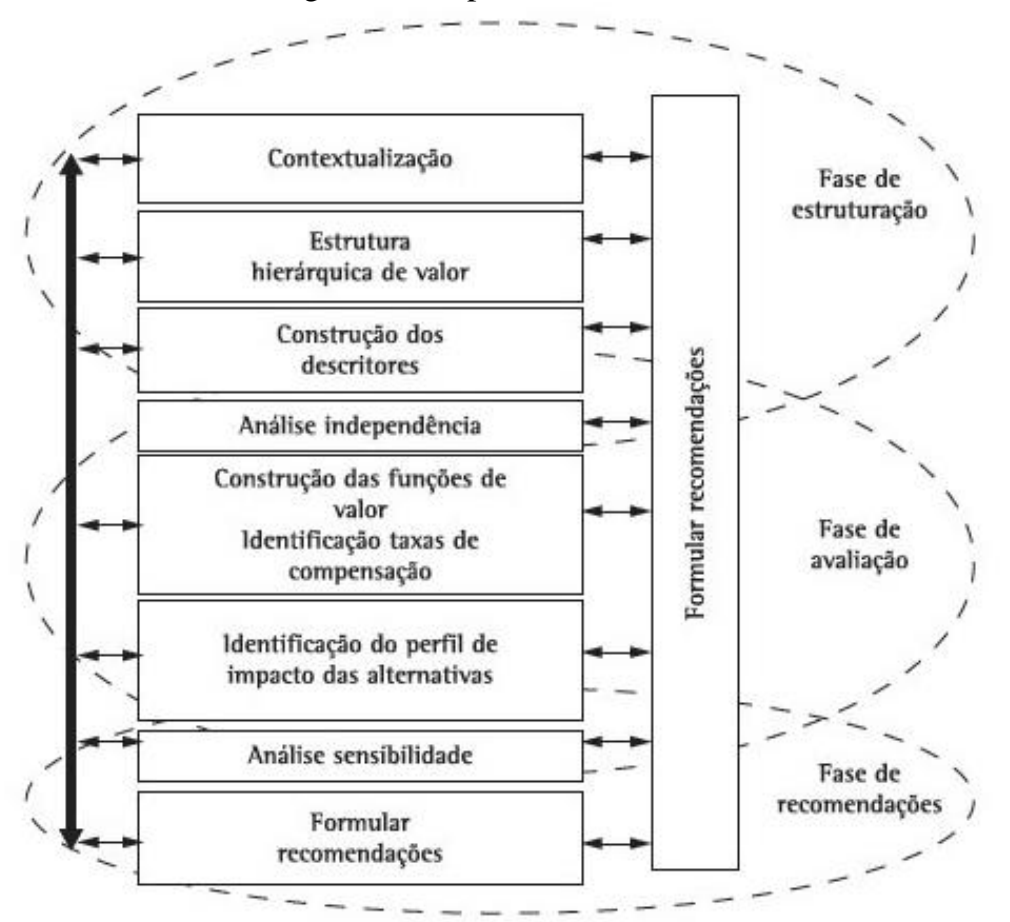

Fonte: Adaptado Ensslin, Dutra e Ensslin (2000, p. 81)

Este estudo visa operacionalizar apenas a fase de estruturação e recomendação, onde a primeira permite a geração de conhecimento para o decisor a respeito do contexto e do problema, identificando quais aspectos são necessários e suficientes segundo sua percepção e preferências, os quais devem ser incorporados na construção do modelo. Essa geração de conhecimento é permitida por meio de diversas entrevistas semiestruturadas buscando a identificação dos aspectos importantes para serem geridos, formulando os indicadores e os níveis de referência, bem como uma estrutura legitimada pelos decisores/gestores. Esta fase permite a identificação do status quo do desempenho em sua forma qualitativa (Valmorbida et al., 2015; Ensslin et al., 2010; Dutra, et al. 2009). A Fase de Recomendações evidencia ações de aperfeiçoamento para o status quo do desempenho e as consequências das ações tomadas, tanto na avaliação global do modelo quanto em cada nível de desempenho individualmente (Ensslin et al.,2013).

O modelo de avaliação proposto foi elaborado de acordo com a percepção do atual Diretor do Departamento, que atua como decisor e é o responsável legal pela gestão do mesmo. As informações foram obtidas através de entrevistas estruturadas realizadas nos meses de maio, junho e julho de 2017, bem como da análise de documentos formais disponibilizados para consulta. 


\section{Contabilidade}

\section{RESULTADOS}

A estrutura organizacional da Universidade Federal de Santa Catarina (UFSC) é composta pela Administração Superior e pela Administração nas Unidades. Como consta em seu Estatuto, a Universidade possui autonomia administrativa, didático-científica, gestão financeira e disciplinar. Autonomia financeira pode ser entendida segundo Garcia (2002) como "a capacidade de gestão e aplicação dos recursos destinados a prover as atividades e serviços do órgão titular da dotação”. Neste contexto a Secretaria de Planejamento e Orçamento (SEPLAN), órgão executivo central, atua como uma Unidade Administrativa da UFSC sendo encarregada do planejamento e da administração financeira da instituição. Em sua composição a SEPLAN conta com o Departamento de Contabilidade e Finanças (DCF) que tem suas atribuições baseadas na execução financeira e na evidenciação contábil da universidade. A Figura 2 apresenta de maneira sintética a estrutura formal do DCF.

Figura 3 - Estrutura do setor

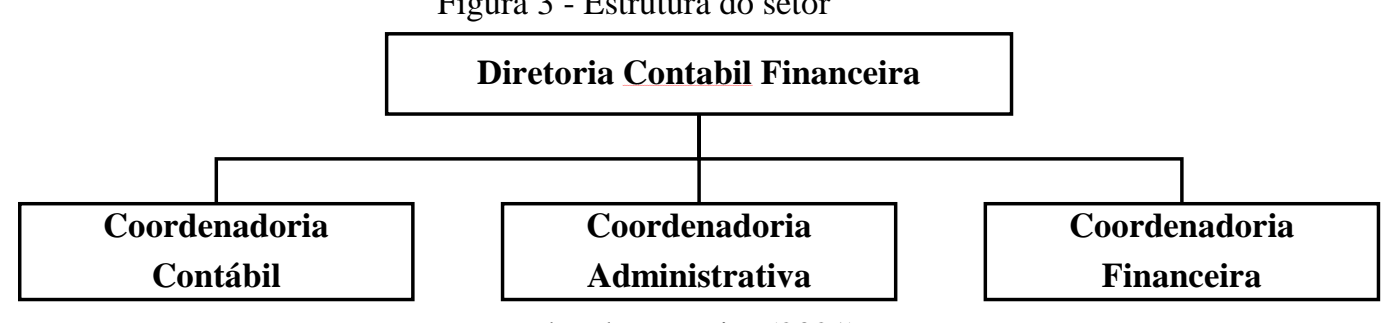

Fonte: Dados da Pesquisa (2021).

As atribuições do Departamento, conforme o Decisor, podem ser resumidas como sendo: Assessorar o Secretário de Planejamento, no que tange às suas atribuições; Superintender as atividades das Coordenadorias do Departamento; Executar atividades inerentes à área e outras que venham a ser delegadas por autoridade competente.

Como participantes na tomada de decisão, os intervenientes do modelo são: o secretário da SEPLAN, pois tem influência direta nas atividades desenvolvidas no setor, visto que o Departamento é uma parte da secretaria; os chefes de setor, visto que esses estão mais próximos das rotinas operacionais e tem responsabilidade sobre o produto final das mesmas; e os Colaboradores do Departamento, sendo esses os responsáveis pela execução das atividades desenvolvidas. O autor desta pesquisa cumpre o papel de facilitador, interagindo com o decisor de modo a construir conhecimento sobre o processo decisório. Por fim, os agidos, aqueles que são influenciados pelas decisões tomadas são divididos em dois grupos: Internos, compreendendo a comunidade universitária, (técnicos 
administrativos, professores e estudantes) e os Externos, a sociedade, os fornecedores e os órgãos reguladores e fiscalizadores. A Tabela 3 apresenta os atores envolvidos no processo.

Tabela 3 - Atores envolvidos no processo

\begin{tabular}{|c|l|l|}
\hline \multirow{2}{*}{ Intervenientes } & Decisor & Diretor do Departamento \\
\cline { 2 - 3 } & Facilitador & $\begin{array}{l}\text { Secretário da Seplan } \\
\text { Chefes de Setor } \\
\text { Colaboradores do Departamento }\end{array}$ \\
\hline & Autor do Trabalho \\
\hline \multirow{2}{*}{ Agidos } & $\begin{array}{l}\text { Externos } \\
\text { Sociedade, Fornecedores, Órgãos Reguladores e } \\
\end{array}$ & $\begin{array}{l}\text { Fiscalizadores. } \\
\text { Internos } \\
\end{array}$ \\
& $\begin{array}{l}\text { Comunidade Universitária } \\
\text { (TAE's, Professores e Estudantes) }\end{array}$ \\
\hline
\end{tabular}

Fonte: Dados da pesquisa (2021).

O rótulo consiste em elaborar o enunciado do problema e deve conter o foco principal do trabalho, indicando o propósito a ser atingido (Ensslin, Montibeller \& Noronha, 2001). Nesta etapa, através da interação entre facilitador e decisor, foi elaborado o seguinte rótulo para o problema: "Metodologia de Apoio na Gestão da Transparência e Acessibilidade da Informação do Departamento de Contabilidade e Finanças”. Partindo da definição do rótulo, foi definido um sumário, que visa apresentar, de maneira estruturada, o campo a ser explorado no estudo. A Tabela 4 apresenta o sumário construído.

Tabela 4 - Sumário

A administração pública brasileira passa por tempos difíceis de escassez de recursos, inúmeros casos de desvio nos órgãos públicos bem como uma falta de credibilidade por parte do serviço público perante a sociedade. Enquanto Autarquia de Regime Especial, vinculada ao Ministério da Educação, a UFSC faz parte da Administração Pública Indireta do Poder Executivo da União e deve observar os Princípios que regem a administração pública, expressos no art. 37 da Constituição da República de 1988: legalidade, impessoalidade, moralidade, publicidade e eficiência, bem como está sujeita a legislação que visa garantir o controle social através transparência e acessibilidade da informação. Neste contexto a transparência e a acessibilidade da informação somam ao desempenho organizacional, aumenta a credibilidade, atende a legislação pertinente e fomenta o controle social.

Conforme Meyer Jr. (1997) assim como as empresas, as universidades brasileiras estão necessitando de uma reformulação gerencial de maneira a posicionar-se de forma mais competitiva no ambiente. Ambiente pressionado pelo Governo por mais eficiência e transparência por parte de seus órgãos, órgãos esses que atuam por diversas vezes com orçamento contingenciado em virtude da escassez de recursos. A exigência por transparência pode ser vista por meio da IN n ${ }^{\circ} 2$ de $06 / 12 / 16$ que exige a divulgação do cronograma dos pagamentos efetuados pelos órgãos pertencentes a esfera federal. Desta maneira, para o diretor do setor um modelo que auxiliasse a tomada de decisão seria de grande utilidade. 
Neste cenário a pesquisa proposta tem por objetivo construir um modelo de gestão interna para o Departamento de Contabilidade e Finanças da UFSC que sirva como ferramenta para o gestor na tomada de decisão buscando maior transparência nas atividades desenvolvidas e nos resultados alcançados.

Tendo em vista que Diretor (decisor) não dispõe de uma formalização dos objetivos a serem alcançados, dos critérios que devem ser levados em consideração para o alcance destes objetivos, será utilizada a metodologia MCDA-C, para desenvolver um modelo personalizado que atenda as necessidades do contexto estudado.

Ao final da pesquisa ter-se-á construído um modelo que permitirá ao gestor do DCF visualizar gráfica e numericamente os aspectos por ele julgado como essenciais para a gestão do departamento evidenciando as performances locais e globais, informando sua situação atual e possíveis recomendações.

Fonte: Dados da pesquisa (2021).

Após a definição do contexto, dos atores e do rótulo do problema, passa-se à construção do modelo propriamente dito, que tem início na identificação dos Elementos Primários de Avaliação (EPAs). Estes são as primeiras preocupações manifestadas pelo decisor quando estes confrontam a situação. Com base nos EPAs foram construídos conceitos que sugerem a direção de preferência, relacionada ao EPA e registra também o seu oposto psicológico (mínimo aceitável do objetivo subjacente), representado pelas reticências (...) que devem ser lidas como "ao invés de”. Neste estudo foram identificados 9 EPA's, sendo estes apresentados na Tabela 5 acompanhados de seus devidos conceitos.

Tabela 5 - Elementos primários de avaliação (EPA’s) e conceitos

\begin{tabular}{|c|c|}
\hline EPA's & Conceitos \\
\hline Diárias & $\begin{array}{l}27 \text { - Garantir o acesso à informação nos pagamentos de diárias.. não } \\
\text { disponibilizar a informação. }\end{array}$ \\
\hline Fornecedores & $\begin{array}{l}28 \text { - Garantir o acesso à informação nos pagamentos aos fornecedores } \\
\text {..não disponibilizar a informação. }\end{array}$ \\
\hline Pagamento & $\begin{array}{l}29 \text { - Garantir o acesso à informação nos pagamentos de bolsas ..não } \\
\text { disponibilizar a informação. }\end{array}$ \\
\hline Integridade & $\begin{array}{l}300 \text { - Garantir a integridade da informação não modificada, inclusive } \\
\text { quanto à origem, trânsito e destino.. Disponibilizar informações não } \\
\text { íntegras. }\end{array}$ \\
\hline Periodicidade & $\begin{array}{l}\text { 7- Efetuar atualizações semanais do site do setor ..atualizar } \\
\text { esporadicamente o site sem uma programação definida. }\end{array}$ \\
\hline Atendimento & $\begin{array}{l}\text { 8- Atender ao público de maneira adequada ..não atender o público de } \\
\text { maneira adequada. }\end{array}$ \\
\hline Controle Social & $\begin{array}{l}303 \text { - Disponibilizar o horário de atendimento e jornada de trabalho de } \\
\text { cada colaborador de maneira visível na entrada do setor.. não evidenciar } \\
\text { as informações necessárias para o controle social. }\end{array}$ \\
\hline Solicitações & $\begin{array}{l}309 \text { - Atender no prazo de } 20 \text { dias as solicitações de informações não } \\
\text { disponíveis imediatamente.. descumprir a legislação. }\end{array}$ \\
\hline Evidenciação & $\begin{array}{l}30 \text { - Garantir o Cumprimento da IN 02/2006 (evidenciar cronologia dos } \\
\text { pagamentos) ..descumprir IN 02/2006. }\end{array}$ \\
\hline
\end{tabular}

Após a construção dos conceitos que representam preocupações estratégicas equivalentes, segundo a percepção do decisor (Ensslin et al., 2010), estes podem ser agrupados em Áreas de Preocupação. Os conceitos foram agrupados em três Pontos de 


\section{Revista \\ UNEMAT de \\ Contabilidade}

v. 10, n. 19,2021

Vista Fundamentais: Publicidade dos Pagamentos, Publicidade de Informações Relevantes e Aspectos Legais. Partindo destes agrupamentos é possível realizar a criação de mapas cognitivos, onde é possível incluir e excluir conceitos por meio do processo de geração de conhecimento permitido pela metodologia MCDA-C. Visando facilitar a análise dos mapas cognitivos, estes foram divididos em clusters e subclusters, sendo que para cada cluster um nome que representa o foco de interesse do decisor foi associado (Ensslin; Neto \& Noronha, 2001). A Figura 4 apresenta o mapa cognitivo com os respectivos clusters criados.

Figura 4 - Mapa cognitivo com os respectivos clusters

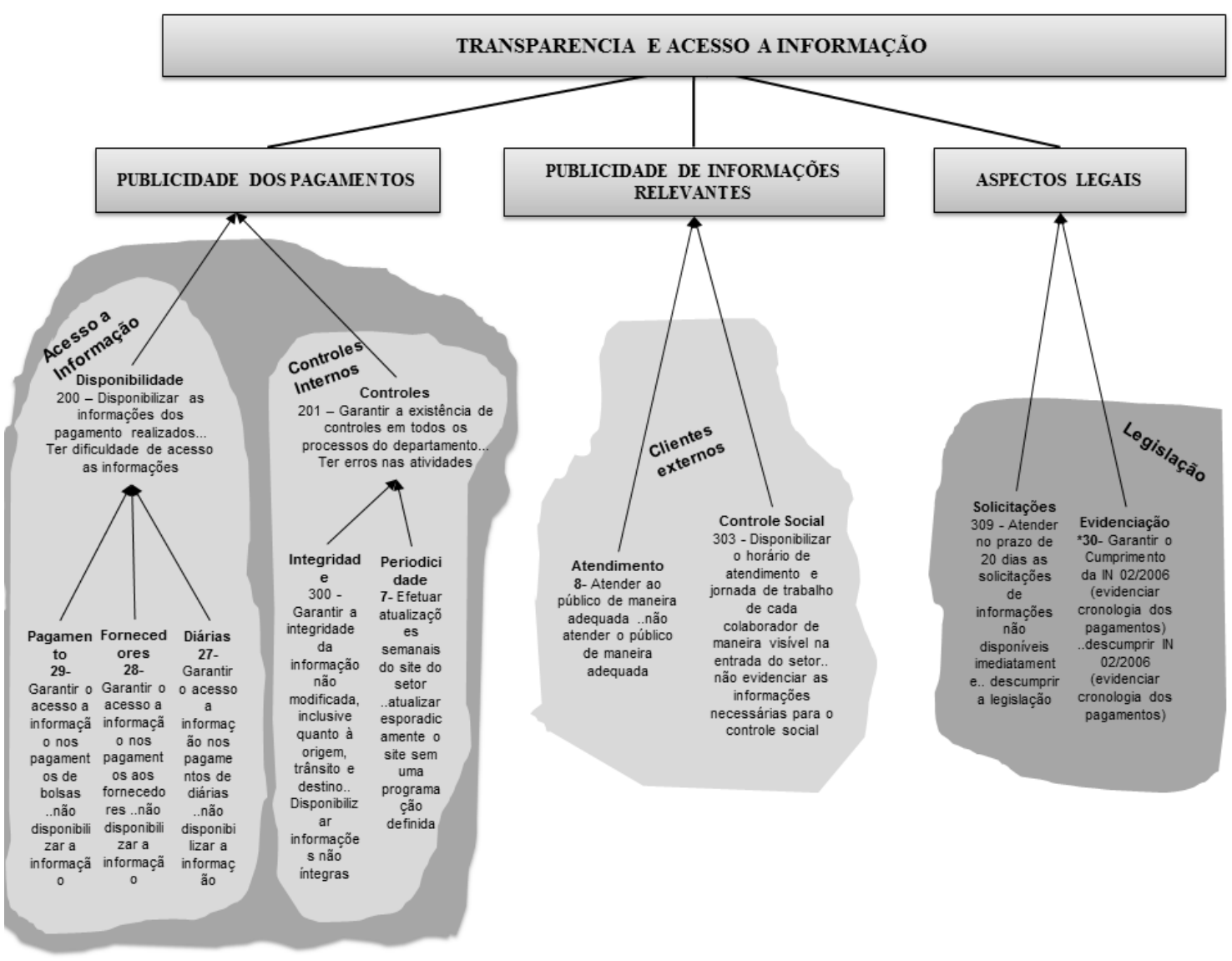

Fonte: Dados da pesquisa (2021)

Após o agrupamento em clusters e subclusters, origina-se a Árvore de Valor com os Pontos de Vistas Elementares (PVEs). Segundo Ensslin, Neto e Noronha (2001) a estrutura arborescente (árvore) utiliza a lógica de decomposição, em que um critério mais complexo de ser mensurado é decomposto em subcritérios de mais fácil mensuração. A Figura 5 apresenta a Árvore de Valor com os Pontos de Vistas Elementares (PVEs) obtida com os dados da pesquisa obtidos neste estudo. 


\section{Contabilidade}

Figura 5 - Árvore de Valor com os Pontos de Vistas Elementares (PVEs)

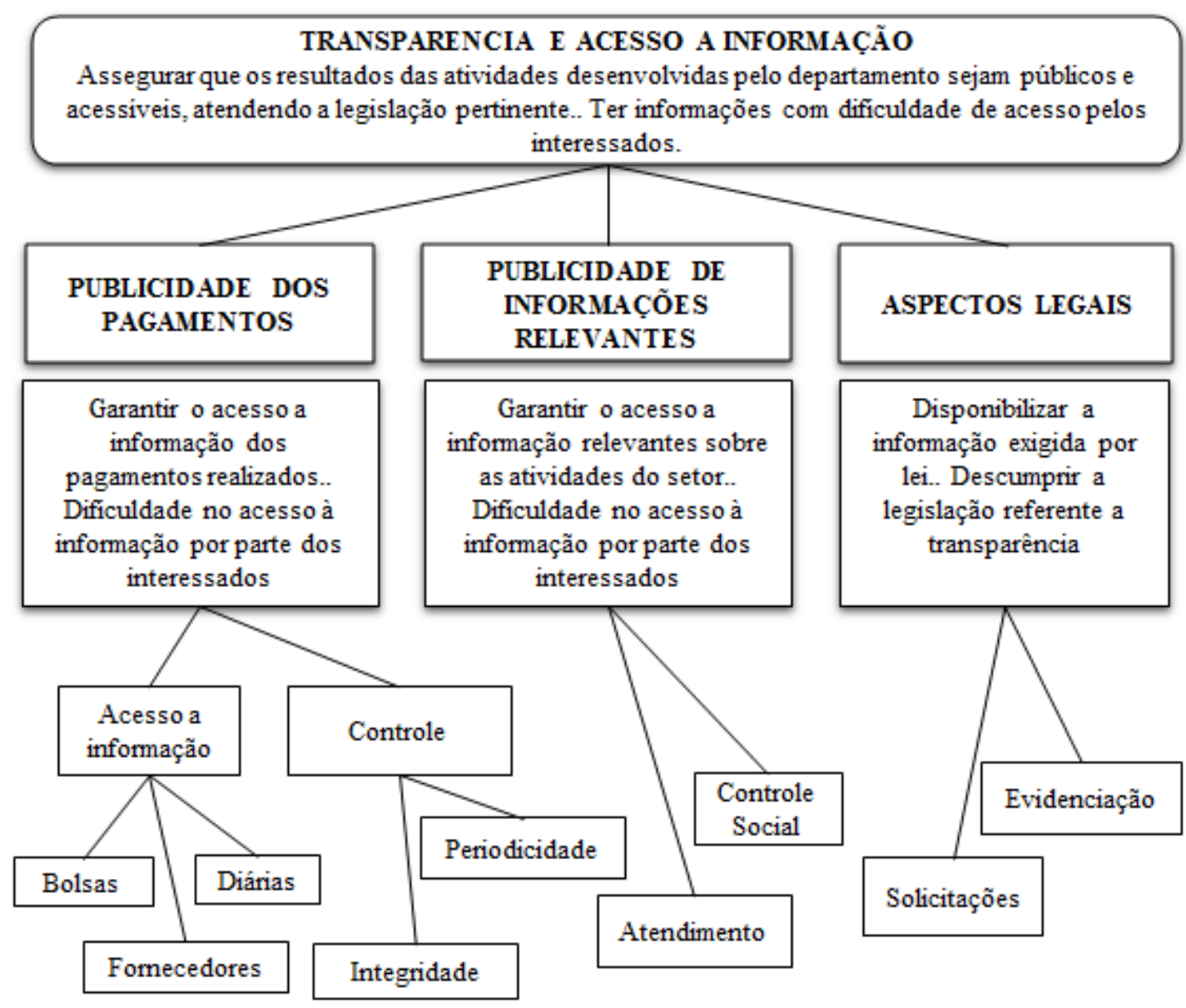

Fonte: Dados da Pesquisa (2021)

Partindo dos Pontos de Vistas Elementares definidos foram construídas as escalas ordinais, denominados descritores na metodologia MCDAC, que possibilitam a medição do desempenho das propriedades de cada PVE que operacionalizam os objetivos apresentados nos mapas cognitivos (Ensslin et al., 2015). A sequência da metodologia prevê como próximo passo o estabelecimento dos níveis de referência, que podem ser "Bom" e "Neutro" permitindo a comparação de desempenho entre os descritores (escalas) (Ensslin; Dutra \& Ensslin, 2000). Desempenhos que impactam em um dos descritores acima do nível de referência "Bom" são considerados de excelência; os que impactarem abaixo do nível de referência "Neutro" são considerados como desempenho comprometedor; e, aqueles que impactam entre os dois níveis de referência são considerados como de desempenho de competitivo (de mercado/esperado) (Ensslin; Neto \& Noronha, 2001). A Figura 6 apresenta a Estrutura Hierárquica de Valor, os descritores e o status quo das atividades do departamento. 


\section{Contabilidade}

Figura 6 - Estrutura Hierárquica de Valor
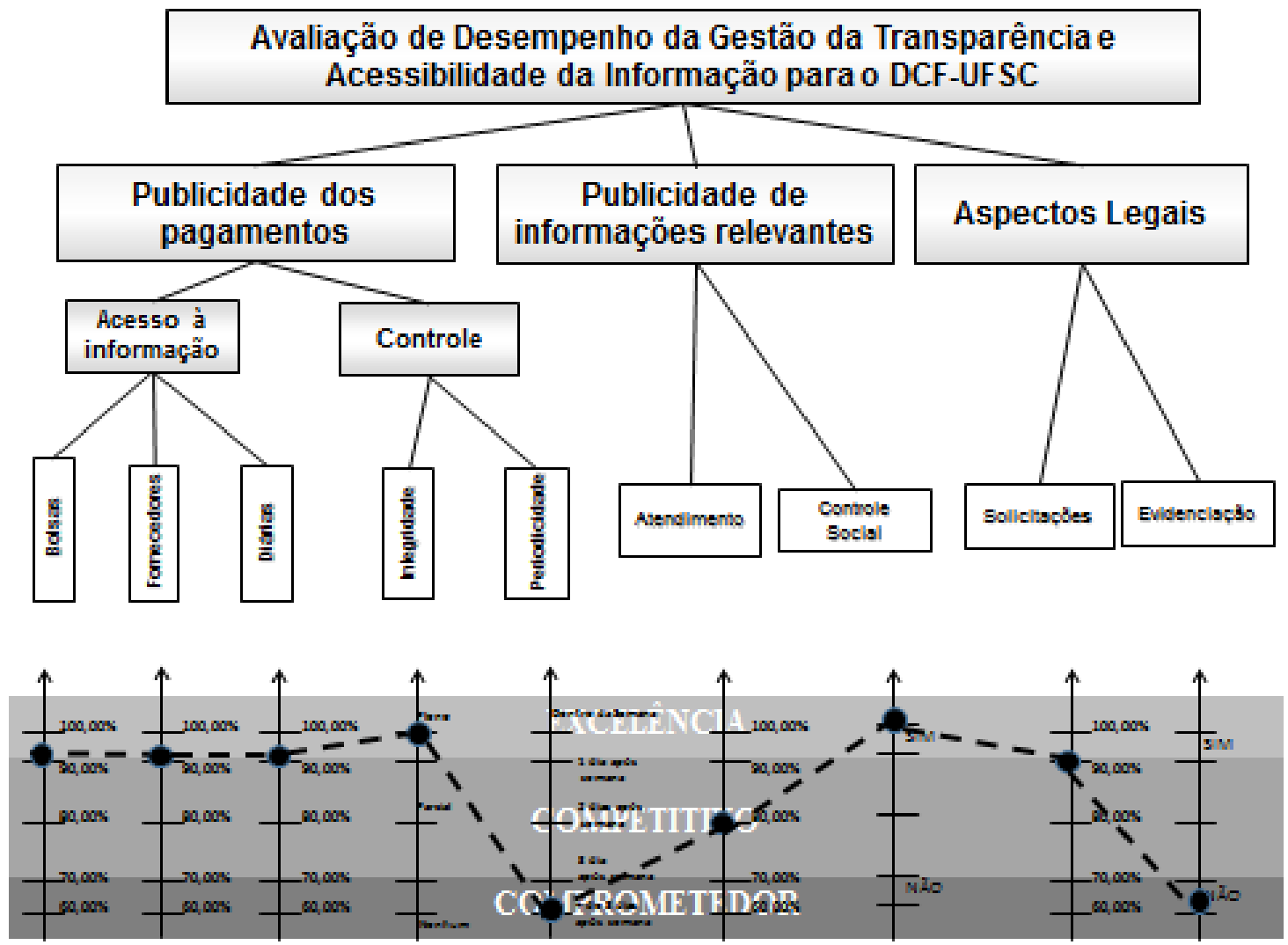

Fonte: Dados da pesquisa (2021)

Na Fase de Recomendações, os indicadores que apresentavam um desempenho no nível comprometedor foram identificados, e ações de melhorias foram propostas para o aperfeiçoamento do desempenho. Os indicadores de desempenho que se encontravam no nível comprometedor foram: (1) Número de dias que ocorre a atualização das informações no site em relação a semana de pagamento; (2) Cumprimento da IN 02/2006 que visa evidenciar a cronologia de pagamentos. A Tabela 6 apresenta as ações de melhorias propostas para alavancar o desempenho da atividade de pesquisa nesses dois indicadores.

Tabela 6 - Ações de Aperfeiçoamento

\begin{tabular}{|c|c|}
\hline PVE & Periodicidade \\
\hline Indicador & $\begin{array}{l}\text { Número de dias que a atualização das informações } \\
\text { no site ocorre em relação a semana de pagamento }\end{array}$ \\
\hline \multicolumn{2}{|r|}{ Ações Propostas } \\
\hline \multicolumn{2}{|c|}{$\begin{array}{l}\text { Capacitar mais colaboradores para estarem aptos a fazerem as atualizações no site, podendo substituir a } \\
\text { pessoa responsável caso não possa fazê-lo. }\end{array}$} \\
\hline \multicolumn{2}{|c|}{$\begin{array}{l}\text { Realizar reuniões mensais com o departamento de Tecnologia da Informação da universidade buscando } \\
\text { automatizar as informações no site. }\end{array}$} \\
\hline Responsável & Coordenadoria Financeira \\
\hline
\end{tabular}




\begin{tabular}{|c|c|c|}
\hline \multicolumn{2}{|l|}{ Prazo de Atendimento } & Até 12 meses \\
\hline \multicolumn{2}{|l|}{ Impacto do Descritor } & $\begin{array}{l}\text { Nível deixaria de ser comprometedor e seria } \\
\text { competitivo }\end{array}$ \\
\hline \multicolumn{2}{|l|}{ PVE } & $\begin{array}{c}\text { Evidenciação } \\
\end{array}$ \\
\hline \multicolumn{2}{|l|}{ Indicador } & $\begin{array}{l}\text { Cumprimento da IN } 02 / 2006 \text { que visa evidenciar a } \\
\text { cronologia de pagamentos. }\end{array}$ \\
\hline \multicolumn{3}{|r|}{ Ações Propostas } \\
\hline \multicolumn{3}{|c|}{$\begin{array}{l}\text { Realizar reuniões semanais com a coordenação financeira para desenvolvimento de relatório de suporte } \\
\text { para evidenciar as exigências da Instrução Normativa. }\end{array}$} \\
\hline \multicolumn{3}{|c|}{$\begin{array}{l}\text { Realizar reuniões mensais com o departamento de Tecnologia da Informação da universidade para } \\
\text { criação de local específico no site para evidenciação. }\end{array}$} \\
\hline Responsável & \multicolumn{2}{|c|}{ Direção } \\
\hline Prazo de Atendimento & \multicolumn{2}{|c|}{ Até 3 meses } \\
\hline Impacto do Descritor & \multicolumn{2}{|c|}{ Nível deixaria de ser comprometedor e seria excelente } \\
\hline
\end{tabular}

As ações de melhorias propostas para os indicadores encontrados no nível comprometedor contribuem para que o desempenho nos descritores deixe o nível comprometedor. A metodologia MCDA-C permite que ações de melhoria sejam propostas para os indicadores com maior contribuição à avaliação global, permitindo que o desempenho da instituição seja aperfeiçoado cada vez mais.

\section{DISCUSSÃO E COTEJAMENTO DE RESULTADOS}

Os desafios enfrentados pelo DCF da UFSC na gestão da transparência e acessibilidade da informação não são exclusivos do setor. Raminho e Colares (2016) constataram na conclusão de seu estudo a necessidade de as instituições analisadas promoverem esforços no sentido de melhorar a qualidade da prestação de contas. No estudo de Costa e Neto (2016) a Instituição, objeto de pesquisa do trabalho, ainda necessita rever suas estruturas visando uma melhor racionalidade e aproveitamento, a fim de integrar os diversos Núcleos e Departamentos que lidam com a área de gestão da informação. Oliveira Bezerra, Borges e Valmorbida (2012) apontam na conclusão de seu trabalho que a divulgação de informações completas é como uma prática que necessita de melhoria por parte da instituição para cumprir seu papel de dar transparência aos autos de gestão.

Na verificação da situação atual do DCF-UFSC os descritores que se encontravam no nível comprometedor estão relacionados a objetivos operacionais comuns em outros estudos. A periodicidade, que diz respeito à atualização das informações no site, foi citada no estudo de Costa (2013), o qual aponta que nem sempre os gestores possuem em mãos e prontamente as informações de que necessitam para tomar decisões, sendo necessária a 


\section{Revista \\ UNEMAT de \\ Contabilidade}

v. 10, n. 19,2021

pesquisa e busca nos sistemas de informação internos e externos ou diretamente com responsável pela geração. Como cada ciclo de vida das informações é conduzido de uma maneira diferente em cada sistema, essa busca e disponibilidade de informações tende a ser comprometida.

Lyrio, Brotti, Ensslin, \& Ensslin (2009) ao propor um modelo baseado na metodologia MCDA-C para avaliar o grau de transparência das demonstrações financeiras publicadas por uma instituição pública de ensino superior brasileira, identificou como um dos EPA's do modelo a Atualização constante das demonstrações financeiras (DF), sendo elaborado o seguinte conceito: Minimizar a defasagem em relação à data de acesso às DFs e à data de sua publicação.

$\mathrm{O}$ atendimento a legislação que regula a transparência na instituição que o departamento estudado faz parte é outro ponto encontrado no trabalho de Carvalho Almeida e Freire (2015) que afirma que grande parte dos organismos públicos apenas disponibilizam os portais como forma de darem uma mínima "satisfação" à população, muitas vezes motivado apenas por razões legais, não reconhecendo os gestores a importância que esse rico instrumento de democratização pode proporcionar. Gama e Rodrigues (2016) destacam na conclusão de seu estudo que a existência de instrumentos que obrigam a transparência ativa não é garantia de sua implementação em curto prazo, o que leva os autores a sugerir a continuidade de pesquisas em médio e longo prazo. Sediyama, de Oliveira Reis e dos Anjos (2016) apontam que o cumprimento das exigências da legislação é facilitado pelo engajamento de todos, propiciando assim um ambiente fértil para promoção da transparência e da accountability.

As ações de melhoria propostas para os descritores em nível comprometedor indicam uma maior integração entre os departamentos, principalmente entre os responsáveis pela tecnologia da informação e o DCF-UFSC. Esteves, Lourenço e Sá (2017) em seu estudo consideram que a tecnologia digital pode ser um bom meio para permitir a comunicação desejada.

\section{CONSIDERAÇÕES FINAIS}

O arcabouço legal referente à Transparência e acessibilidade da informação dos órgãos públicos demonstra por meio de seus inúmeros, normativos, leis e princípios a importância e a preocupação a respeito do tema. Contudo, conforme Gama e Rodrigues 


\section{Revista

(2016), a existência de instrumentos que obrigam a transparência ativa não é garantia de sua implementação em curto prazo. Por esta razão os gestores e responsáveis devem buscar o cumprimento da legislação e realizar as alterações necessários em seus órgãos. Foi esta necessidade e preocupação por parte do Diretor do Departamento Financeiro da UFSC somado ao fato de que um dos autores deste trabalho fazer parte do mesmo departamento que viabilizaram a execução deste estudo. A possibilidade da construção de conhecimento proporcionada pela Metodologia Multicritério de Apoio à DecisãoConstrutivista (MCDA-C) foi um dos fatores determinantes na escolha desta para o cumprimento do objetivo que visa responder a seguinte questão: Quais os critérios a serem considerados em um modelo que pretenda apoiar a gestão da transparência e acessibilidade da informação para o departamento de contabilidade e finanças da UFSC?

Com base nos resultados obtidos foi possível evidenciar que a Metodologia Multicritério de Apoio à Decisão Construtivista - MCDA-C, mostrou-se capaz de capturar e formalizar as preocupações, as crenças e os valores do Departamento Financeiro da UFSC, conforme as percepções do Diretor do departamento (decisor).

A definição do perfil de desempenho possibilitou verificar quais as atividades que estavam com desempenho excelente, competitivo ou comprometedor. Sendo que o cotejamento de resultados demonstrou que as atividades com desempenho comprometedor, em sua essência, não eram exclusividade do setor. O cotejamento de resultados demonstrou semelhanças dos resultados com outros estudos.

A pesquisa foi desenvolvida e aplicada em um Departamento que pertence a uma Instituição Federal Pública de Ensino Superior e expressa percepções do decisor para dentro do contexto avaliado, sendo assim limita-se a construção de um modelo específíco para o apoio à gestão da transparência e acessibilidade da informação, assim, a replicação do modelo deve ser realizada com adequações necessárias à realidade de cada instituição.

\section{REFERENCIAS}

ARAÚJO, Samuel Souza; DOS SANTOS MATOS, Lucas; ENSSLIN, Sandra Rolim. Sistema de avaliação de desempenho para apoio à gestão da coordenadoria dos processos licitatórios de um Hospital Universitário. REVISTA AMBIENTE CONTÁBIL-Universidade Federal do Rio Grande do NorteISSN 2176-9036, v. 13, n. 1, p. 244-262, 2021.

ASATO, Anita Ortega et al. Avaliação institucional de uma universidade federal: proposta de um modelo multicritério construtivista de apoio à gestão. Revista Meta: Avaliação, v. 12, n. 36, p. 719-745, 2020.

AZEVEDO, LYRIO; LUNKES, E. ALBERTON. An analysis of the level of transparency of 
federal universities' websites in the south of Brazil. Public Administration Research, v. 5, n. 42, p. 42$52,2016$.

BANA E COSTA, Carlos A. Três convicções fundamentais na prática do apoio à decisão. Pesquisa Operacional, v. 13, n. 1, p. 9-20, 1993.

BANA E COSTA, C. A. Vansnick, Uma abordagem ao problema de construção de uma função de valor cardinal. 1995.

COELHO, Gabriel Nilson. Balanced Scorecard: Uma análise bibliométrica com base na Web of Science de 1992-2017. Revista UNEMAT de Contabilidade, v. 8, n. 15, 2019.

COSTA, Carlos A. BANA; PIRLOT, Marc. Thoughts on the future of the multicriteria field: Basic convictions and outline for a general methodology. In: Multicriteria analysis. Springer, Berlin, Heidelberg, 1997. p. 562-568.

COSTA, Carlos A. Bana et al. Decision support systems in action: integrated application in a multicriteria decision aid process. European Journal of Operational Research, v. 113, n. 2, p. 315-335, 1999.

CORRÊA CHAVES, Leonardo et al. Construção de modelo para apoiar o processo de desenvolvimento de um sistema de apoio à decisão. JISTEM-Journal of Information Systems and Technology Management, v. 17, 2020.

GOMES, L. F. A. M., GOMES C. F. S. Tomada de Decisão Gerencial-Enfoque Multicritério. 5.a edição - Editora Atlas. São Paulo, 2014.

Bezerra, R., Borges, L. J., \& Iesbik Valmorbida, S. M. Análise das prestações de contas na internet da Universidade do Estado de Santa Catarina. Revista Gestão Universitária na América LatinaGUAL, 5(1), 2012.

BRASIL, Decreto $n^{\circ}$ 5.482, de 30 de junho de 2005. Dispõe sobre a divulgação de dados e informações pelos órgãos e entidades da Administração Pública Federal, por meio da Rede Mundial de Computadores: Internet. Diário Oficial da União, Brasília, 1 jul. 2005. Disponível em: http://www.planalto.gov.br/ccivil_03/_Ato2004-2006/2005/Decreto/D5482.html . Acesso em 07/02/2021.

BRASIL, Lei Complementar $n^{\circ}$ 131, de 27 de maio de 2009. Determina a disponibilização, em tempo real, de informações pormenorizadas sobre a execução orçamentária e financeira da União, dos Estados, do Distrito Federal e dos Municípios. Diário Oficial da União, Brasília, 28 maio 2009. Disponível em: http://www.planalto.gov.br/ccivil_03/leis/lcp/lcp131.htm> Acesso em 07/02/2021

BRASIL, Presidência da república. Casa Civil. Subchefia para Assuntos jurídicos (2011): Lei Complementar $\mathrm{n}^{\text {o }}$ 101, de 4 de maio de 2011 (Lei de Responsabilidade Fiscal). Estabelece normas de finanças de finanças públicas voltadas para a responsabilidade na gestão fiscal e dá outras providências. Brasília. Disponível em:<http://www.planalto.gov.br/ccivil_03/leis/lcp/lcp101.htm>. Acesso em 07/02/2021

CARVALHO ALMEIDA, S. E., \& Freire, I. M. Lei de Acesso à Informação e transparência: proposta de inclusão de informações no Portal Transparência UFPB. Pesquisa Brasileira em Ciência da Informação e Biblioteconomia, 10(2), 2015.

COSTA, F. D. D. O. Gestão de conteúdo como apoio ao processo de tomada de decisão em Instituição Federal de Ensino Superior, (2013).

COSTA, G. B., \& Neto, P. A. B. (2016). O direito de acesso à informação pública e a gestão da informação nas universidades: estudo de caso em uma instituição pública de ensino superior. Interface, 13(2).

CROZATTI, J. Conceitos de mensuração e conceitos de Avaliação de Desempenho: a teoria versus a prática em empresas brasileiras. 2002. 265 f. Tese (Doutorado em Contabilidade) - Universidade de São Paulo, São Paulo, 2002.

DUTRA, A. (2003) Metodologia para avaliar e aperfeiçoar o desempenho organizacional: incorporando a dimensão integrativa à MCDA Construtivista-Sistêmico- Sinergética. 2003. Tese (Doutorado em Engenharia da Produção) Universidade Federal de Santa Catarina, Florianópolis. 
ENSSLIN, Leonardo; NETO, Gilberto Montibeller; NORONHA, Sandro MacDonald. Apoio à decisão: metodologias para estruturação de problemas e avaliação multicritério de alternativas. Insular, 2001.

ENSSLIN, Leonardo; DUTRA, Ademar; ENSSLIN, Sandra Rolim. MCDA: a constructivist approach to the management of human resources at a governmental agency. International transactions in operational Research, v. 7, n. 1, p. 79-100, 2000.

ENSSLIN, Leonardo; NETO, Gilberto Montibeller; NORONHA, Sandro MacDonald. Apoio à decisão: metodologias para estruturação de problemas e avaliação multicritério de alternativas. Insular, 2001.

ENSSLIN, Leonardo; CAMPOS, Marcelo L. A prática do aprendizado organizacional. Revista Gestão Industrial, v. 2, n. 1, p. 59-69, 2006.

ENSSLIN, Leonardo et al. ProKnow-C, Knowledge Development Process-Constructivist: processo técnico com patente de registro pendente junto ao INPI. Brasil:[sn], 2010.

ENSSLIN, L., Giffhorn, E., Ensslin, S. R., Petri, S. M., \& Vianna, W. B. (2010). Avaliação do desempenho de empresas terceirizadas com o uso da metodologia multicritério de apoio à decisãoconstrutivista. Pesquisa Operacional, 30(1), 125-152.

ESTEVES, L., Lourenço, R., \& Sá, P. (2017). Transparência das Instituições de Ensino Superior: Comunicação com a Comunidade Empresarial. In Atas da Conferência da Associação Portuguesa de Sistemas de Informação (Vol. 17, No. 17, pp. 158-173).

FRANCO, L. Alberto; MONTIBELLER, Gilberto. Facilitated modelling in operational research. European Journal of Operational Research, v. 205, n. 3, p. 489-500, 2010.

GAMA, Janyluce Rezende; RODRIGUES, Georgete Medleg. Transparência e acesso à informação: um estudo da demanda por informações contábeis nas universidades federais brasileiras. TransInformação, v. 28, n. 1, p. 47-58, 2016.

GARCIA, Emerson. A autonomia financeira do Ministério Público. Revista dos Tribunais, v. 803, p. 63, 2002.

IGARASHI, D. C. C.; Ensslin, S. R.; Ensslin, L.; Paladini, E.P. A qualidade do ensino sob o viés da avaliação de um programa de pós-graduação em contabilidade: proposta de estruturação de um modelo híbrido. RAUSP. Revista de Administração, v. 43, p. 117-137, 2008.

LYRIO, Maurício Vasconcellos Leão et al. Proposta de um modelo para avaliar o grau de transparência das demonstrações financeiras publicadas por uma Instituição Pública de Ensino Superior Brasileira: a abordagem da Metodologia Multicritério de Apoio à Decisão Construtivista. Journal of Accounting, Management and Governance, v. 11, n. 1-2, 2009.

MEYER JR, V. (1997) Gestão para a qualidade e qualidade na gestão: o caso das universidades. Florianópolis: Seminário Internacional de Gestão pela Qualidade em Universidades.

BEZERRA, Rafael Oliveira; BORGES, Loreci João; VALMORBIDA, Sandra Mara lesbik. Análise das prestações de contas na internet da Universidade do Estado de Santa Catarina. Revista Gestão Universitária na América Latina-GUAL, v. 5, n. 1, p. 66-82, 2012.

NETO, Orion Augusto Platt; DA CRUZ, Flávio; VIEIRA, Audí Luiz. Transparência das contas públicas: um enfoque no uso da internet como instrumento de publicidade na UFSC. Revista Contemporânea de Contabilidade, v. 3, n. 5, p. 135-146, 2006.

RICHARDSON, R. J. Pesquisa social: métodos e técnicas. São Paulo: Atlas. Rios, TA (1997). Ética e Competência. 1999.

GAMA, Janyluce Rezende; RODRIGUES, Georgete Medleg. Perspectivas e Desafios na Transparência das Contas Públicas: um estudo numa Instituição de Ensino Superior brasileira. Encontros Bibli: revista eletrônica de biblioteconomia e ciência da informação, v. 21 , n. 45 , p. 2-20, 2016.

RAMINHO, Adalberto Hott; COLARES, Ana Carolina Vasconcelos. Disclosure da informação contábil na gestão patrimonial dos bens móveis das instituições públicas de ensino 
superior federais brasileiras. ConTexto, v. 16, n. 33, p. 113-127, 2016.SEDIYAMA, G. A. S., de Oliveira Reis, A., \& dos Anjos, D. A. GESTÃO TRANSPARENTE DA INFORMAÇÃO EM UMA INSTITUIÇÃO PÚBLICA BRASILEIRA.

DA SILVA LEITE, Aldecir. Sistema de Informação Contábil nas Fundações e o SICAP como Instrumento da Transparência Administrativa-Um estudo de caso. Revista Magsul de Administração e Contabilidade, v. 2, n. 1, p. 133-146, 2017.

VALMORBIDA, Sandra Mara lesbik et al. Avaliação de desempenho como instrumento de apoio ao gerenciamento da diretoria de planejamento e administração de uma universidade pública federal: uma perspectiva multicritério. 2012.

LOPES, Anderson Brunheira. Método para análise de viabilidade de obras públicas com auxílio da metodologia multicritério de apoio à decisão. Revista Técnico-Científica, n. 19, 2019.

LAUDON, Kenneth C.; LAUDON, Jane Price. Sistema da Informação Gerenciais. 7 ed. São Paulo: Pearson Prentice Hall, 2007.

STONER, James A. F. e FREEMAN, R. Edward. Administração. $5^{\text {a }}$ ed. Rio de Janeiro: Prentice Hall do Brasil, 1995.

OLIVEIRA, Djalma de Pinho Rebouças. Sistemas de Informações Gerenciais. $7^{\text {a }}$ ed. São Paulo: Atlas, 2001.

MEGGINSON, Leon C., MOSLEY, Doanald C. e Pietri Jr., Paul H. Administração: Conceitos e Aplicações. São Paulo: Harper \& Row do Brasil, 1986. 